\title{
Trapped in a vicious loop: Toll-like receptors sustain the spontaneous cytokine production by rheumatoid synovium
}

\author{
Shahla Abdollahi-Roodsaz, Fons AJ van de Loo and Wim B van den Berg* \\ See related research by Nic An Ultaigh et al., http://arthritis-research.com/content/13/1/R33
}

\begin{abstract}
Synovial tissue of patients with rheumatoid arthritis

(RA) spontaneously produces several cytokines,

of which a fundamental role in joint inflammation

and destruction has been established. However,

the factors sustaining this phenomenon remain

poorly understood. In a recent report, blockade of

Toll-like receptor 2 (TLR2) was found to inhibit the

spontaneous release of inflammatory cytokines by

intact RA synovial explant cultures. Adding to the

recent evidence implicating other TLRs (in particular,

TLR4), this observation highlights the potential of TLRs

as therapeutic targets to suppress the local production

of multiple cytokines and to control the chronic

inflammatory loop in RA.
\end{abstract}

Spontaneous production of inflammatory cytokines, along with tissue-destructive enzymes, is one of the unique characteristics of rheumatoid arthritis (RA) synovial tissue. The discovery of this phenomenon by Brennan and colleagues in 1989 has led to the understanding of the central role of tumor necrosis factor-alpha (TNF $\alpha$ ) and its position upstream of interleukin-1 (IL-1) and IL-6 in RA. As major mediators of joint inflammation and destruction, these cytokines have become targets of novel therapeutics in recent years; however, the factors driving their production remain largely unknown. In the previous issue of Arthritis Research E Therapy, Nic An Ultaigh and colleagues [1] reported that Toll-like receptor 2 (TLR2) mediates spontaneous cytokine release from RA ex vivo synovial explant cultures.

*Correspondence: w.vandenberg@reuma.umcn.nl

Rheumatology Research and Advanced Therapeutics, Department of

Rheumatology, Radboud University Nijmegen Medical Centre, PO Box 9101, 6500 HB Nijmegen, The Netherlands
TLRs are a family of pattern recognition receptors evolved to recognize conserved microbe-associated molecular patterns. Signal transduction through TLRs controls the expression of a number of proinflammatory cytokines, including TNF $\alpha$, IL-1 and IL-6, chemokines such as IL-8, and matrix metalloproteinases, factors that are spontaneously and chronically produced by dissociated RA synovial mononuclear cell cultures $[2,3]$. Some TLRs such as TLR2, TLR3, and TLR4 can be activated by endogenous 'danger' molecules associated with inflammation and tissue destruction, and many of these molecules have been found in joints and serum of patients with RA and show a positive correlation with disease activity scores $[4,5]$. As TLR-mediated inflammatory response may induce further tissue damage and promote the generation of additional endogenous ligands, it has been hypothesized that TLRs can engender a self-sustaining inflammatory loop responsible for chronic progression of RA [6,7].

Using synovial explant cultures in which tissue structure and complexity are preserved, Nic An Ultaigh and colleagues [1] introduced TLR2 as a driving force behind spontaneous cytokine production in RA. First, the authors showed that a monoclonal antibody against TLR2 can inhibit, as expected, cytokine production induced by a TLR2 agonist in RA peripheral blood and synovial fluid mononuclear cells. Importantly, this antibody significantly suppressed the spontaneous release of TNF $\alpha$, interferon-gamma (IFN- $\gamma$ ), and IL- $1 \beta$ and IL- 8 by synovial tissue explants to an extent comparable to that of the TNF inhibitor adalimumab. These observations suggest the relevance of TLR2 in RA pathogenesis.

A growing body of evidence links TLR to spontaneous cytokine production by RA synovium. Besides enhanced expression of TLR2, those of TLR3, TLR4, and TLR7 in RA synovial tissue have been demonstrated before [4]. TLR4 has previously been found to drive spontaneous production of TNF $\alpha, \mathrm{IL}-1 \beta$, and IL-10 by intact RA synovial tissue explants [8]. In addition, TLR4 contributes 
to the development of the highly pathogenic Th17 cells and IL-17 production and promotes severe autoimmune spontaneous arthritis in mice [8]. Along these lines, TLR4 blockade suppresses joint inflammation and destruction in experimental arthritis, even during the established phase [9].

Spontaneous production of proinflammatory cytokines and matrix metalloproteinases by RA synovial membrane cells can also be inhibited by overexpression of the dominant-negative form of MyD88 adaptor-like (Mal), an adaptor molecule specifically involved in TLR4 signaling and recently reported not to be essential for TLR2 signaling $[10,11]$. Furthermore, TNF $\alpha$ production by RA synovial membrane cells could be blocked by imiquimod and the serotonin receptor antagonist mianserin, compounds suggested to inhibit TLR8 [12].

So far, the only in vivo evidence supporting TLR involvement in the vicious inflammatory cycle in patients comes from a humanized model in which intact RA synovial explants were transplanted into severecombined immunodeficient (SCID) mice. In this model, specific blockade of TLR4 markedly suppressed the spontaneous cytokine production and the severity of inflammation in the transplants to the same extent as adalimumab [13]. A head-to-head comparison of different TLRs in the valuable ex vivo model used by Nic An Ultaigh and colleagues and in the humanized RA-SCID model will help clarify their relative contributions to the vicious inflammatory loop in RA.

Of note, the studies mentioned above all used relatively small $(\leq 12)$ numbers of patients. From a clinical perspective, however, it is important to consider the substantial heterogeneity among patients with RA. Microarray analysis of RA synovial tissues has revealed a noteworthy subdivision of patients, with one group having abundant expression of genes involved in adaptive immune response and another group expressing stromal cellrelated gene clusters with a tissue remodeling signature [14]. The presence of an adaptive immune response is of high relevance in the case of TLR2, for which expression on regulatory $\mathrm{T}$ cells (Tregs) and a direct role in Treg proliferation and function have been reported [15]. In the autoimmune $\mathrm{T}$ cell-mediated arthritis that develops as a result of IL-1 receptor antagonist deficiency, TLR2 protects mice from severe arthritis by controling Treg function and by counteracting the production of IFNY and IL-17 [8]. This implies that TLR2 blockade might have detrimental effects on restraining autoimmunity in a subset of patients. Finally, our unpublished observations indicate TLR2 as a negative regulator of $\mathrm{Fcy}$ receptor response in macrophages, a function with important consequences in conditions in which immune complexes are present. In fact, the diverse pro- and anti-inflammatory functions of TLR2 may imply a dual role in arthritis, depending on the cells and the processes involved. However, the unambiguous proinflammatory function of TLR4 appears to provide a solid therapeutic target with consistent benefit.

In conclusion, the report by Nic An Ultaigh and colleagues supports the recently introduced concept of the involvement of TLRs in perpetuation of the chronic inflammatory loop in RA in which endogenous ligands serve as triggers. Unraveling the divergent functions of these receptors and their relative roles in subpopulations of patients with RA is just the dawn of TLR-targeted therapy.

\section{Abbreviations}

IFN- $\gamma$, interferon-gamma; IL, interleukin; RA, rheumatoid arthritis; SCID, severecombined immunodeficient; TLR, Toll-like receptor; TNFa, tumor necrosis factor-alpha; Treg, regulatory $T$ cell.

\section{Competing interests}

WBvdB holds a patent on a TLR4 inhibitor. The other authors declare that they have no competing interests.

Published: 30 March 2011

\section{References}

1. Nic An Ultaigh S, Saber TP, McCormick J, Connolly M, Dellacasagrande J, Keogh B, McCormack W, Reilly M, O'Neill LA, McGuirk P, Fearon U, Veale DJ: Blockade of Toll-like receptor 2 prevents spontaneous cytokine release from rheumatoid arthritis ex vivo synovial explant cultures. Arthritis Res Ther 2011, 13:R33.

2. Kawai T, Akira S: The role of pattern-recognition receptors in innate immunity: update on Toll-like receptors. Nat Immunol 2010, 11:373-384.

3. Brennan FM, McInnes IB: Evidence that cytokines play a role in rheumatoid arthritis. J Clin Invest 2008, 118:3537-3545.

4. Brentano F, Kyburz D, Gay S: Toll-like receptors and rheumatoid arthritis. Methods Mol Biol 2009, 517:329-343.

5. Shiozawa K, Hino K, Shiozawa S: Alternatively spliced EDA-containing fibronectin in synovial fluid as a predictor of rheumatoid joint destruction. Rheumatology (Oxford) 2001, 40:739-742.

6. Abdollahi-Roodsaz S, Joosten LA, Koenders MI, van den Brand BT, van de Loo $F A$, van den Berg WB: Local interleukin-1-driven joint pathology is dependent on toll-like receptor 4 activation. Am J Pathol 2009, 175:2004-2013.

7. van den Berg WB, van Lent PL, Joosten LA, Abdollahi-Roodsaz S, Koenders MI: Amplifying elements of arthritis and joint destruction. Ann Rheum Dis 2007, 66 Suppl 3:iii45-iii48.

8. Abdollahi-Roodsaz S, Joosten LA, Koenders MI, Devesa I, Roelofs MF, Radstake TR, Heuvelmans-Jacobs M, Akira S, Nicklin MJ, Ribeiro-Dias F, van den Berg WB: Stimulation of TLR2 and TLR4 differentially skews the balance of T cells in a mouse model of arthritis. J Clin Invest 2008, 118:205-216.

9. Abdollahi-Roodsaz S, Joosten LA, Roelofs MF, Radstake TR, Matera G, Popa C, van der Meer JW, Netea MG, van den Berg WB: Inhibition of Toll-like receptor 4 breaks the inflammatory loop in autoimmune destructive arthritis. Arthritis Rheum 2007, 56:2957-2967.

10. Sacre SM, Andreakos E, Kiriakidis S, Amjadi P, Lundberg A, Giddins G, Feldmann M, Brennan F, Foxwell BM: The Toll-like receptor adaptor proteins MyD88 and Mal/TIRAP contribute to the inflammatory and destructive processes in a human model of rheumatoid arthritis. Am J Pathol 2007, 170:518-525.

11. Kenny EF, Talbot S, Gong M, Golenbock DT, Bryant CE, O'Neill LA: MyD88 adaptor-like is not essential for TLR2 signaling and inhibits signaling by TLR3. J Immunol 2009, 183:3642-3651.

12. Sacre SM, Lo A, Gregory B, Simmonds RE, Williams L, Feldmann M, Brennan FM, Foxwell BM: Inhibitors of TLR8 reduce TNF production from human rheumatoid synovial membrane cultures. J Immunol 2008, 181:8002-8009.

13. Abdollahi-Roodsaz S, Koenders MI, Joosten LA, van de Loo FA, van den Berg WB: Toll-like receptor 4 blockade ameliorates murine and humanized 
models of rheumatoid arthritis: a comparison with IL-1 and TNF blockade. Paper presented at: 73rd Annual Scientific Meeting of the American College of Rheumatology/Association of Rheumatology Health Professionals; 20 October 2009; Philadelphia, PA. Presentation 1897.

14. van der Pouw Kraan TC, van Gaalen FA, Kasperkovitz PV, Verbeet NL, Smeets TJ, Kraan MC, Fero M, Tak PP, Huizinga TW, Pieterman E, Breedveld FC, Alizadeh AA, Verweij CL: Rheumatoid arthritis is a heterogeneous disease: evidence for differences in the activation of the STAT-1 pathway between rheumatoid tissues. Arthritis Rheum 2003, 48:2132-2145.
15. Sutmuller RP, den Brok MH, Kramer M, Bennink EJ, Toonen LW, Kullberg BJ, Joosten LA, Akira S, Netea MG, Adema GJ: Toll-like receptor 2 controls expansion and function of regulatory T cells. J Clin Invest 2006, 116:485-494.

doi:10.1186/ar3287

Cite this article as: Abdollahi-Roodsaz S, et al:: Trapped in a vicious loop: Toll-like receptors sustain the spontaneous cytokine production by rheumatoid synovium. Arthritis Research \& Therapy 2011, 13:105. 